\title{
THE LEADERSHIP CHARACTERISTICS AMONG HEADMASTERS TOWARDS PRIMARY SCHOOL STUDENTS LIVING WITH HIV/AIDS IN KLANG VALLEY
}

\author{
Khairul Amar Razali \\ Institute of Educational Leadership, Faculty of Education, University Malaya \\ Corresponding Author Email: amar.razali@gmail.com
}

\begin{abstract}
Although the HIV/AIDS epidemic in Malaysia has been lingering for over three decades since its first reported case in 1986, due to continuous medical advancement and social awareness, people living with HIV/AIDS now have a longer life span and are able to live a relatively normal life. School-age HIV-positive children can obtain formal education like their peers; however, this is not without challenges, especially in terms of stigma and discrimination. This is where school leadership comes to play its part. The purpose of this research is to explore the leadership characteristics of the headmasters towards students living with HIV/AIDS in schools. This study adopted a qualitative methodology where six headmasters of primary schools in Klang Valley were selected using purposive sampling and interviewed. The interview schedule contained four open-ended questions with an overall purpose of examining the characteristics of the headmasters' leadership towards students living with HIV/AIDS at the schools. Thirteen leadership characteristics emerged from the analysis: "having knowledge and understanding", "providing knowledge and creating understanding", "meticulous", "pragmatic", "reliable", "ethical", "considerate", "impartial", "supportive", "attentive", "collegial", "building collaboration", and "consulting others". This research serves as a base for future studies on leadership effectiveness, specifically towards students living with HIV/AIDS, as well as for improving guidelines on managing HIV/AIDS cases in schools.
\end{abstract}

Keywords: Leadership Characteristics, Headmasters, Primary Schools, HIV/AIDS, Students

\section{INTRODUCTION}

The Malaysian government is committed to benefit students with special needs through the improvisation of financing physical and teaching resources by 2025 as stated in the Malaysia Education Blueprint 2013-2025. Teachers of students with specific needs will undergo additional training in order to help them recognise the specific challenges of these students and to plan according to their needs (Ministry of Education Malaysia [MOEM], 2012). Furthermore, one of the key activities underlined in the National Strategic Plan for Ending AIDS 2016-2020 is the enhancement of the delivery of HIV education and awareness in the school curriculum and co-curriculum (Ministry of Health Malaysia [MOHM], 2015).

At the United Nations Special Session on HIV/AIDS in June 2001 (United Nations General Assembly [UNGA], 2001, p. 10), attended by leaders of various countries including Malaysia, a declaration was made that each country would: 
"By 2003, develop and by 2005 implement national policies and strategies to: build and strengthen government, family, and community capacities to provide a supportive environment for orphans and boys and girls infected and affected by HIV/AIDS, including by providing appropriate counselling and psychosocial support; ensuring their enrolment in school and access to shelter, good nutrition, health, and social services on an equal basis with other children; to protect orphans and vulnerable children from all forms of abuse, violence, exploitation, discrimination, trafficking, and loss of inheritance."

The Ministry of Education Malaysia has introduced several programmes to ensure that children with specific needs have access to education, such as the Inclusive Education Programme and the School-in-Hospital Programme (MOEM, 2018). These programmes, however, are not specialised for students living with HIV/AIDS at schools.

\section{Children Living with HIV/AIDS}

The Ministry of Health Malaysia surveillance data shows that since the first case of HIV was reported in 1986 until the end of 2014, 105,189 people were infected with HIV, 21,384 people had AIDS, and 17,096 died from AIDS. At the end of 2014, 88,093 people were living with HIV (MOHM, 2015), and 956 were children under the age of 13 (MOHM, 2016). With the availability of advance therapies for HIV and various support programmes, more HIV/AIDS infected, and affected children are entering school age and are able to receive formal education. However, living with HIV/AIDS has its many challenges other than their physical conditions, especially in terms of socio-economics, psychosocial functioning, and mental development. Unless this cycle of poverty, exclusion, and inequality is broken, there is no guarantee that children living with HIV/AIDS will have an equal opportunity like that of normal children in experiencing a brighter future.

\section{RESEARCH STATEMENT}

This research focuses its lens on the educational aspect of this issue, specifically, the leadership characteristics of the headmasters towards students living with HIV/AIDS. Children who are affected from parents with HIV/AIDS or infected by it have been living under severe negative perceptions from general public as well as within the school environment, which could affect their performance in school. One of the causes may be due to the lack of knowledge among the public regarding HIV/AIDS. The situation may go from bad to worse if the school leaders, especially the headmasters themselves, are not aware about the severity of the condition and how to provide support and cater to the needs of students living with HIV/AIDS. At present, there is no official guideline specifically for the management of students living with HIV/AIDS.

The research is designed with the objective to explore the leadership characteristics from the viewpoint of a selected group of headmasters when dealing with students living with HIV/AIDS. The findings of this research serve as a base for future studies on leadership effectiveness, specifically towards students living with HIV/AIDS, as well as for improving guidelines on managing HIV/AIDS cases in schools. 


\section{LITERATURE REVIEW}

\section{The Impacts of HIV/AIDS on Children's Education}

HIV/AIDS can affect a child's education in various ways due to physiological, psychological, or economic distress. Poverty is one of the risk factors of HIV, with high incidences reported among the poor (Buot et al., 2014). It magnifies the effect of HIV/AIDS on children through changes occurring in the family due to illness and death. The children may not get enough basic needs and nutrition to support proper growth and development, nor access to healthcare (Richter, 2004). Moreover, because of this financial shortage, many of the orphans could not complete school.

Even for those who did manage to continue their education, with the responsibilities that the children have to shoulder to support the households, their focus on education is lessened (Richter, 2004). HIV-infected or affected children in the Kenyan study (Akunga et. al., 2000) were found to have a low school attendance rate due to sickness and having to take care of family members. Out of 129 primary and secondary school students, $52 \%$ of the boys and $48 \%$ of the girls infected with or affected by HIV/AIDS reported reduced performance in school, linked to low concentration, lack of studying time, and loss of motivation and hope. Akunga et. al. (2000) also observed that $56 \%$ of the boys and $44 \%$ of girls infected with or affected by HIV/AIDS had to quit school not only because of their disease, but also due to financial strain and social stigma.

Children living with HIV/AIDS also face many psycho-social issues, including loss of parental love and guidance, sadness and fear, relationship changes, as well as mistreatment (Akunga et. al., 2000). The loss of a loved one is linked to various internal psychological problems, including anxiety, rumination, depression, survivor's guilt, low self-esteem, and social isolation (Richter, 2004). On top of that, many people living with HIV/AIDS have already been isolated by their community, friends, and even family, thus amplifying the consequences (Akunga et. al., 2000).

Furthermore, the children receive a negative perception from the public and are exposed to severe discrimination (Akunga et. al., 2000; Richter, 2004; MOHM, 2015). In a survey conducted by the Ministry of Health Malaysia in 2014, when the respondents were asked if they "think children living with HIV should be able to attend school with children who are HIV negative", at least $19 \%$ of them answered "No" or "It depends" (MOHM, 2015). The findings of the Integrated Bio-Behavioural Survey in 2014 indicated that up to $50 \%$ of people living with HIV had faced verbal abuse, and up to $20 \%$ had been harassed, discriminated, and even physically abused (MOHM, 2015).

HIV infection can also impair neurodevelopment and cognitive functioning in children. Although the survival rate has improved with the advent of antiretroviral therapy, Boyede, Lesi, Ezeaka, \& Umeh (2013) commented that various studies continue to show persistent neurodevelopmental delay in children, causing poor cognitive functioning and poor performance at school. In another study by Cohen et al. (2015), HIV-positive children had poorer cognitive functioning compared to healthy children, especially in their intelligence, how fast they process information, and their attention and working memory. 


\section{The Role of Educators in Supporting Students Living with HIV/AIDS}

Akunga et. al. (2000) remarked that schools do not have sufficient HIV/AIDS education resources, and the teachers lack the necessary knowledge, understanding, and skills of HIV/AIDS and its education, and are often themselves not good role models, particularly in terms of HIV/AIDS mistreatment. There is a need for schoolchildren to have more guidance and support, especially by their educators. Kelly (2000) mentioned that young people require special counselling and psychological support to fully develop their personality. The school should extend its mission to support HIV/AIDS stricken children more than just academically. Kelly (2000) also suggested that there is a need for the school to adopt a flexible timetable to cater for HIV/AIDS children, and to bring the school to the children who cannot possibly attend under their circumstances.

A number of organisations, such as the National Children's Bureau (Conway, 2005) and the Tameside Metropolitan Borough Council in the United Kingdom (Tameside Metropolitan Borough Council, 2018), are now offering guidelines in dealing with HIV/AIDS in schools. Members of a HIV-friendly school should, for instance, be well informed about the disease, be able to administer first aid and the required hygiene control measures, recognise the children's right to education, ensure fair treatment, be aware of the procedures for HIV disclosure, and respect confidentiality (Conway, 2005). This is where the leadership of the school headmasters comes to play its part in providing a supportive school environment for the children.

\section{Studies in Educational Leadership}

Woods and Martin (2016) observed several leadership behaviours that were beneficial in the education field: "Leader as a Change Agent", "Leader as the Vision Creator", and "Leader as a Supporter of Strategies". "Educating the Whole Child" is another important theme that emerged from their research, which includes providing basic needs, personalizing academic interventions, emphasizing on reading, extending academic time, and building relationship.

Effective leadership among the educators raises school performance to an exceptional level of excellence, regardless of the students' socio-demographic factors that may influence the students' academic and non-academic performance, as demonstrated in a study conducted by Raihani (2008) in three different schools of various backgrounds: urban and outskirt, middle and lower class, previously lower ranking and higher ranking. In a narrative case study conducted by Woods and Martin (2016), the outcome of effective leadership was observed in the performance of school's poor students: over $70 \%$ of the student populations qualified for free or reduced meals, and within that group, over $65 \%$ obtained the top two levels of achievement on the Missouri Assessment Program.

Effective leadership does not only result in a better student support and higher academic performance, but it also contributes to the increase in teachers' satisfaction and motivation, which is one of the important factors in ensuring quality teaching and learning. Veeriah, Chua, and Siaw (2017) reported positive correlation between principals' transformational leadership skills and teacher affective commitment. The principals placed importance on the sharing of vision and mission, as well as 
establishing school culture that contributes towards strengthening the organisation as a whole.

Although educational leadership is a growing field of research, many of the studies, including those mentioned previously, focused on leadership characteristics among school leaders and educators and their effectiveness in terms of the school performance and motivation in general. Studies on vulnerable children or those with special needs are not as common. In one of these studies, Soulis (2009) noted three characteristics that are essential among special educators in teaching children with learning disabilities: good communicate skill, instructional ability, and a well-rounded personality. As of date, there is no report on the leadership characteristics especially in dealing with students living with HIV/AIDS.

\section{METHODOLOGY}

This case study focused on exploring the leadership characteristics of headmasters in primary schools through a qualitative approach. Information and evidences were gathered from multiple other sources, such as literature reviews, consultations with HIV/AIDS shelter home and advocacy group, and individual observations. In order to understand the handling of students living with HIV/AIDS in the schools, semistructured interviews were conducted. Using qualitative analysis, the researcher examined the interview responses from participants as the primary data of the study. Each case was analysed in depth for common and emerging themes to provide a reliable answer to the research questions. (Creswell, 2013; Hatch, 2002; Marshall \& Rossman, 2010).

\section{Instrumentation}

Data was collected using interviews. The interview schedule contained four openended questions developed with an overall purpose of analysing the effectiveness of the headmasters' leadership towards students living with HIV/AIDS at the schools. The interview schedule was piloted to ensure that the questions are relevant, sensitive, and can strongly contribute to the research. This was done by referring the interview questions with experts from the Malaysian AIDS Council, the caretakers of a shelter home with children living with HIV/AIDS, and retired school headmasters and teachers. Additionally, the pilot study was conducted to ensure that the questions are clear and grammatically correct, and that the right expression of the Malay language is used. The interview schedule was validated by two people fluent in both English and Malay languages.

\section{Sampling}

The participants of this study were headmasters of six primary schools in Klang Valley. The study implemented a purposive sampling approach, in which the sample schools were selected based on the information provided by a shelter home that caters for children living with HIV/AIDS. Because of the irregular nature of HIV/AIDS cases, purposive sampling allowed the researcher to specifically target headmasters in schools attended by students living with HIV/AIDS. The researcher has taken into consideration of research bias by selecting a broad range of participants consisting of 
similar proportions of both genders, with two to seven years of experience as a headmaster.

\section{Data Collection}

Approval and consent were obtained from the Ministry of Education, the State Education Department, and the school headmasters. The interviews were carried out mostly in Malay, as this is the main medium of instruction in public primary schools. However, some of the participants (Headmaster 1 and Headmaster 2) spoke in English, so they were interviewed in English. Frequently mentioned opinions were noted in a reflective journal for coding purposes, together with other observations.

\section{Data Analysis}

The first step in data analysis was transcribing the audio recording and translating the Malay transcripts into English by a third party, qualified translator. The transcripts were then shown to the participants to obtain their approval before using the interview data for the purpose of this research. Once approval and validation have been confirmed, all verbatim responses from the interviews were compiled and extensive readings of the responses were conducted for coding purposes. Emerging and recurring themes were identified and later grouped according to categories. This thematic analysis provided the answer to the research question on the headmasters' leadership characteristics towards students living with HIV/AIDS, based on the headmasters' opinion.

\section{FINDINGS}

\section{Participants}

A total of six headmasters from selected primary schools in Klang Valley were interviewed in person at their respective schools using the interview schedules, which have been developed specifically for this study. All interviews were conducted at the headmasters' office during regular office hours. The interviews were recorded after obtaining approvals from the headmasters.

Additional information such as years of leadership experience as a headmaster and their working experience as a teacher was also collected. The participants who were interviewed have been in the leadership positions for an average length of 4.8 years and have accumulated an average of 22.8 years of teaching experience. The summary of the participants' information can be found in Table 4.1.

\section{Leadership Characteristics of Headmasters towards Students Living with HIV/AIDS}

From the interview sessions with the headmasters, thirteen themes emerged as the leadership characteristics towards students living with HIV/AIDS, which were further grouped into six main categories: 1) "importance of knowledge", 2) "proper actions", 3) "responsibility", 4) "confidentiality", 5) "supportiveness", and 6) "relationship". 
Table 4.1: Participants' information

\begin{tabular}{lccc}
\hline Participant & Gender & $\begin{array}{c}\text { Leadership } \\
\text { Experience } \\
\text { (In Years) }\end{array}$ & $\begin{array}{c}\text { Teaching } \\
\text { Experience } \\
\text { (In Years) }\end{array}$ \\
\hline Headmaster 1 & Male & 7 & 30 \\
Headmaster 2 & Male & 7 & 27 \\
Headmaster 3 & Female & 5 & 30 \\
Headmaster 4 & Female & 3 & 15 \\
Headmaster 5 & Male & 5 & 26 \\
Headmaster 6 & Male & 2 & 9 \\
Mean & & 4.8 & 22.8 \\
\hline
\end{tabular}

\section{Importance of Knowledge}

Two leadership characteristics were categorised under "importance of knowledge": "having knowledge and understanding" and "providing knowledge and creating understanding". When dealing with HIV/AIDS cases, headmasters should have good knowledge and understanding by maintaining awareness of the situation in the school, being knowledgeable and open minded, and making the effort to obtain full understanding of the students' circumstances and needs, as mentioned by the headmasters:

"If you ask my opinion, at least the Head should be informed." [Headmaster 1]

"For me, knowledge and openness is important for an administrator, especially the headmaster or principal, in dealing with this issue, accept students who have the HIV disease." [Headmaster 6]

"We have to ask their family background, on how she took care of the child at previous school." [Headmaster 6]

Not only that they have proper knowledge understanding, they also provide knowledge and create understanding among the school members by increasing awareness and disseminating information. Headmaster 4 mentioned that "education for the school management as well as the teachers... are two crucial factors because the teachers will be the one handling the child." The headmasters also address the concerns from the school members

"I also have to tell my teachers, the type of control they need to do to get ready. I am not the only one who knew. If something happens and my teachers do not know, it poses a risk to them." [Headmaster 5] 
"...l would inform them that we have taken precautions and this is something that has been given approval by the doctors and also the state department on terms of safety of their children and there's nothing to worry, they are normal children." [Headmaster 1]

\section{Proper Actions}

Two leadership characteristics were categorised under "proper action": "meticulous" and "pragmatic". A "meticulous" headmaster is described as having and following clear procedures, being prepared and taking safety precaution when dealing with HIV/AIDS cases. Headmaster 2 cited that "the most important concept is helping these students, where [they] should first get clear guidelines from the authorities, so that what [they] do is based on the procedures that have been set, in the hope not to cause problems in future." This concurred with Headmaster 4's view:

"Of course, number one, I have to go back to the policy of the school." [Headmaster 4]

Headmaster 4 also mentioned the importance of being prepared and the "need to educate [themselves] on at least how to support a child with HIV/AIDS, should they come to [the] school, so that at least they can have proper education and...be part of the society in the future." It is also the responsibility of the headmasters to take safety precautions for the benefit of the school:

"But at the same time, I need to take precaution on safety of the other children as well." [Headmaster 1]

"But, there are controlling steps that I need to emphasise on, for example, I need to know the type of control that I need to do."

[Headmaster 5]

The second leadership characteristic in this category, "pragmatic", comprises being practical and realistic. This is well observed in a discussion with by Headmaster 2 regarding the need and viability of having a special class or school just for the HIV/AIDS students:

"We also need to check the ability of the government in carrying out construction or development classes or special schools for them. If the number is relatively large such as those special class pupils, it is better to have a special class or special school related. It is more convenient in terms of control and knowledge. It depends on our ability... If there is a school or if the school's capacity is quite limited and it makes the pupils go far away from the parents, might as well we prepare a special class like as we have in mainstream schools. A special class, not necessarily a special school." [Headmaster 2] 


\section{Responsibility}

Another leadership characteristic that emerged from the data was being "reliable", which is described as the headmaster being aware of responsibility and showing good example as the leader of the school. Headmaster 6 stressed on this by saying:

"Do not boycott the child. Our job is to educate them and to support them...For me, knowledge and open-mindedness is important so that there is no stigma of prejudice or exclude them from an early stage by headmaster. If the headmaster has already practise these attitudes, subordinates will start differentiate students." [Headmaster 6]

\section{Confidentiality}

Being "ethical", which is described as respecting of the students' privacy and being concern of the negative outcome if confidentiality was breached, is very important in the management the students living with HIV/AIDS in the school. Headmaster 5 stressed on this point strongly:

"...As we know, these students have dignity and personal rights must be protected, confidentiality must be maintained. And I must make sure my teachers to maintain the confidentiality of these students, it is not to be known by the other students because we might able to accept, but we worried the parents of the pupils cannot accept." [Headmaster 5]

This opinion is shared by Headmaster 1, who voiced the need to protect the students' image in this case:

"The information on this child should be confidential as well. The rest, it should not be disclosed. It will affect the child's image in school." [Headmaster 1]

\section{Supportiveness}

Four leadership characteristics were categorised under "supportiveness": "considerate", "impartial", "supportive", and "attentive". A "considerate" headmaster shows concern on the students' well-being, as explained by Headmaster 6:

"I will monitor if the child is suddenly looking depressed, I will refer him or her to counsellor, but without notifying the child's condition. I will know how the child is because I will monitor." [Headmaster 6]

A "considerate" headmaster also sympathises with the students', as voiced by Headmaster 5, saying that "as humans, we are sorry for those unfortunate kids." Not only that, empathy and care for the students' future are what one of the main traits of leadership practised by the headmasters. 
"If they sit only in their group, I felt sorry for they will not be able to expand their mindset, because they only spend time with the similar type of people. If they interact with the outside world, perhaps they may know how to distinguish good and bad. I feel this is better for them to learn about life." [Headmaster 3]

Being "impartial" comprises providing equal opportunity and giving fair treatment, as mentioned by some of the headmasters:

"In terms of the school scope, what I can see is basically it is providing the children the opportunity to attend schools more than to highlight on HIV/AIDS actually." [Headmaster 1]

"I think children with HIV/AIDS should be given the opportunity to live a normal life like other normal kids." [Headmaster 3]

"So we are not allowed to have prejudices, we do not ostracise, isolate; just act as usual..." [Headmaster 6]

In relation to this, the idea of inclusivity is also favoured among some of the headmasters. For example, Headmaster 4 explained that "eventually we want them to work and be part of society. If they go to just this kind of [separate] school, they are still not being part of the society. [We] are still discriminating them, in a way. [We] are still limiting their scope in what they are capable of doing." Headmaster 3 cited that having a separate class or school is "not a healthy condition" and believed that it is not suitable because "they will be kind of isolated. They will not live a normal life. The will mingle among them only. They do not mingle with outsiders".

Another important aspect of leadership being "supportive", which consists of providing assistance to the students and cooperating with guardians, as discussed by Headmaster 4:

"...See how we can also work with the parents of the child who's having AIDS - how they are supporting their child at home or if the child is with organisation, how to go about supporting the child." [Headmaster 4]

Headmaster 4 was also willing to go the extra mile for the students in the case of rejection from other school members:

[If the board of governance discontinue the students] "I would be very sad of course, because I think there are still ways that we can go about...I would try to see how best to still keep this child at the school." [Headmaster 4]

The responsibility to provide support to the students lies not only with the headmasters. Headmaster 6 suggested the involvement of school counsellors and teachers who are aware of the students' status in motivating the students, as well as working towards improvement to cater to the students' need: 
"School counsellors should play a role, likewise the Islamic teachers. If they knew, I think moral support should be given to these students... What the child encountered in the previous school, we will try to fix it here." [Headmaster 6]

Coupled with "supportive", being "attentive" is also an important skill possessed by the headmasters. "Attentive" is described as catering to specific needs, giving personalised attention, and protecting the children's wellbeing.

I believe that if they have a special school which caters their needs, it will be proper for them." [Headmaster 1]

"I do not have experience in handling pupils with HIV/AIDS, but for me they are categorised as pupils with special needs. Which means we should be give the same attention to them as of such students in special class." [Headmaster 2]

"[Special school] is to ensure an easy control and they do not feel as if in the mainstream school where they are being ridiculed." [Headmaster 5]

\section{Relationship}

Three leadership characteristics were categorised under "relationship": "collegial", "building collaboration", and "consulting others". "Collegial" comprises maintaining good relationship and creating unity within the school community.

"I think there should be close relationships with these students. At least we know, parents will believe in us..." [Headmaster 6]

"My motto is one family shares the same container. Which means one family one place, meaning we make it a happy place for everyone." [Headmaster 5]

A part of collegiality is taking care of everyone's interest, as stressed by Headmaster 4:

"As the school principal, I have to take care interest of everybody, not just the teachers, all the students at school, and also the parents...at the same time putting up the necessary measures to support the child and to support the others, to ensure that the school is inclusive enough for child with HIV/AIDS." [Headmaster 4]

School leaders also play an important role in "building collaboration", including collaborating with the authority and establishing cooperation between stakeholders, as demonstrated by Headmaster 2 and Headmaster 6 :

"We have a group called Plan for Individual Education, where parents, administrator which is the headmaster, and GPK need to sit together in designing children's education and to gain their best advice from the 
Ministry of Health. If needed and possible, it is better to also get advice from the NGOs concerned." [Headmaster 2]

"In terms of the involvement, the Ministry of Health does play a role, but sometimes we have to call them. They actually do not know what the school wants. But if there are certain kinds of things that we need, we can simply call them." [Headmaster 6]

In managing HIV/AIDS cases in the schools, headmasters can bridge the gap in knowledge and need and by "consulting others", including the authority, experts, guardians, and other fellow parents.

"I would like to consult with the doctors on how to deal with this kind of children, what are the special needs that these children need to be done-medication and so on-and what are the complications that they have that we need to cater then." [Headmaster 1]

"...I will liaise with the Pejabat Pendidikan Daerah and related parties such as the Ministry of Health for guidelines or controls that are clearly associated with this situation." [Headmaster 2]

"We still will get the say from our Parent-Teacher Association because they would represent the parents at the school. Their support is also very important." [Headmaster 4]

"I have to meet the parents. I want to see how much information they give to their children." [Headmaster 6]

\section{Recurring Themes}

From thirteen leadership characteristics that emerged from the data analysis, three were mentioned by all six participants: "providing knowledge and creating understanding", "meticulous", and "impartial" (Table 4.2). Other commonly mentioned characteristics were "consulting others", "ethical", "considerate", "attentive", "collegial", "building collaboration", "having knowledge and understanding", "supportive", and "pragmatic". Only one participant made a comment in relation to being "reliable" in handling students living with HIV/AIDS.

Table 4.2: Frequency of leadership characteristics

\begin{tabular}{|c|c|c|c|c|c|c|c|c|}
\hline \multicolumn{2}{|c|}{ Leadership Characteristic } & \multicolumn{6}{|c|}{ Headmaster } & \multirow[t]{2}{*}{ Frequency } \\
\hline & & 1 & 2 & 3 & 4 & 5 & 6 & \\
\hline 1. & $\begin{array}{l}\text { Providing } \\
\text { knowledge and } \\
\text { creating } \\
\text { understanding }\end{array}$ & / & / & / & / & / & / & 6 \\
\hline 2. & Meticulous & / & / & / & / & / & / & 6 \\
\hline 3. & Impartial & / & / & l & / & / & / & 6 \\
\hline 4. & Consulting others & / & / & / & & / & / & 5 \\
\hline 5. & Ethical & / & & / & & / & / & 4 \\
\hline
\end{tabular}




\begin{tabular}{|c|c|c|c|c|c|c|c|c|}
\hline 6. & Considerate & / & & / & & / & / & 4 \\
\hline 7. & Attentive & / & I & / & & / & & 4 \\
\hline 8. & Collegial & & & / & / & / & / & 4 \\
\hline 9. & $\begin{array}{l}\text { Building } \\
\text { collaboration }\end{array}$ & / & I & & / & & / & 4 \\
\hline 10. & $\begin{array}{l}\text { Having knowledge } \\
\& \text { understanding }\end{array}$ & / & I & & & & / & 3 \\
\hline 11. & Supportive & & & & / & / & / & 3 \\
\hline 12. & Pragmatic & & / & I & & & & 2 \\
\hline 13. & Reliable & & & & & & / & 1 \\
\hline
\end{tabular}

\section{DISCUSSION}

\section{Leadership Characteristics in Dealing with Students Living with HIV/AIDS}

Based on the headmasters' personal view of dealing with students living with HIV/AIDS, there are thirteen leadership characteristics that emerged from the data analysis: "having knowledge and understanding", "providing knowledge and creating understanding", "meticulous", "pragmatic", "reliable", "ethical", "considerate", "impartial", "attentive", "supportive", "collegial", "building collaboration", and "consulting others". Three recurrent characteristics are mentioned by all of the six headmasters: "providing knowledge and creating understanding", "meticulous", and "impartial". The three characteristics have been identified as the key leadership characteristics of this study.

In Malaysia, openly discussing HIV/AIDS is still a taboo (Tham \& Hasmah, 2015). HIV/AIDS stigma and discrimination still exist in Malaysia until today. Young Malaysian adults have only moderate knowledge on HIV/AIDS (Wong, Chin, Low, \& Jaafar, 2008). Thus, in addressing the stigma towards students living with HIV/AIDS at school, "providing knowledge and creating understanding" is important. Headmasters who exhibit this characteristic take lead in organising campaigns in schools to create more awareness, disseminate information, and address concerns. Educational or recreational activities can be organised to increase the awareness among the school communities. Parents and the local communities can also be involved through programmes such as HIV/AIDS fundraising walk or marathon. Bass (1985) wrote that a leader who focuses on "creating understanding" will be able to motivate their followers to contribute more than what has been initially expected. This can be achieved by raising the awareness on the meaning and importance of an idea or initiative and the ways to achieve the goals.

The campaigns and activities held by the school to provide knowledge and create understanding are also indirectly related to building relationships, where other leadership characteristics were observed in this study, such as "collegial", where school culture is born, and members act as a family unit, as well as "building collaboration" with others. Both characteristics encourage positive and supportive learning environment in school, as observed by Velarde (2017) in international schools in Malaysia. In the study, school leaders played an important role in initiating and inviting people to work together regardless of their differences. In terms of HIV/AIDS, there are a lot of non-governmental organisations (NGOs) and advocacy 
groups that have been set up to assist and provide further information and support, such as the Malaysia AIDS Council (MAC), Positive Malaysian Treatment Access \& Advocacy Group (MTAAG+), Malaysia, and UNICEF, as well as government agencies such as the Ministry of Health.

The second leadership characteristic mentioned by all the headmasters is "meticulous". Based on the study, the descriptions of this leadership characteristic are having clear procedures, being prepared, and taking safety precautions. Sahenk (2010) listed related characteristics of an effective headmaster: they set and apply definitive rules, evaluate needs, and take their time to observe and give instructions. Due to the absence of official guidelines from the Malaysian authorities in dealing with HIV cases in schools, the headmasters must be able to create strategic plans to make sure that safety precautions are met when dealing with HIV/AIDS cases. School stakeholders, such as the teachers, students, and parents, should also be involved in ensuring that these plans can be properly executed.

In addition, the third leadership characteristic mentioned by all six headmasters is being "impartial", which includes providing equal opportunity, giving fair treatment, and focusing on inclusiveness. According to the World Declaration on Education for All (United Nations Educational, Scientific and Cultural Organization [UNESCO], 1990, p. 4), Article 3.1 states that "basic education should be provided to all children, youth, and adults". In the same declaration (UNESCO, 1990, p. 5), Article 3.4 states that "an active commitment must be made to removing educational disparities". Under this leadership characteristic, the sample headmasters emphasised that students living with HIV/AIDS are allowed and given the chance to attend school and integrate with other normal children in regular public schools. All students should be treated fairly, and teachers should not discriminate students based on their background or disabilities. In the corporate world, fairness has a big impact on workers' trust, which in result will enhance the positive working environment and level of productivity (Elm, 2003). The author postulates that fair treatment in the education of vulnerable children and those with special needs -in this case, students living with HIV/AIDSwill also have a positive impact on the children's level of trust and motivation in school.

\section{Practical Implementation}

These studies on leadership characteristics and their effectiveness can be adapted in real life situation with training programmes. A study by Warren and Kelsen (2013) has shown that leadership coaching is possible; they had observed significant increase of principal capacity in nine leadership responsibilities-input, affirmation, relationship, visibility, situational awareness, communication, optimiser, ideals/beliefs, and culture-and positive improvement in student achievement after the principals had undergone a specialised training. Coaching can be done by having an experienced former school leader to provide leadership coaching to the current principals with the best practice of leadership characteristics that has been proven, in order to smoothen the transitional period and provide them with the tools to upgrade the students' learning experience, and thus, performance. 


\section{CONCLUSION}

This research was initiated mainly to explore the leadership characteristics shown by the headmasters towards students living with HIV/AIDS. Thirteen leadership characteristics emerged as themes from the interview responses. These characteristics are "having knowledge and understanding", "providing knowledge and creating understanding", "meticulous", "pragmatic", "reliable", "ethical", "considerate", "impartial", "supportive", "attentive", "collegial", "building collaboration", and "consulting others". The leadership characteristics that emerged from this research spans were grouped into six categories: "importance of knowledge", "proper actions", "responsibility", "confidentiality", "supportiveness", and "relationship".

The thirteen leadership characteristics share a common intent of having the best interest of students living with HIV/AIDS in mind, as these children living with HIV/AIDS require support and guidance for their wellbeing and growth. However, this research only highlights these leadership characteristics in general. More studies can be conducted to further explore the effectiveness of these leadership characteristics in a practical setup, for example, in studying academic performance of students living with HIV/AIDS.

Additionally, the study can be expanded to include responses from other stakeholders, such as guardians, teachers, and counsellors. Further studies can also be carried out to investigate whether the same leadership characteristics can be applied to other categories concerning health conditions or physical disabilities.

Leadership is a set of skills that can be taught and learned. Once the effectiveness has been proven in future research, these leadership characteristics can be adopted into training modules for headmasters, teachers, and school counsellor in particular, to implement a suitable support structure. Trainees can undergo psychological tests to determine their own strengths and weaknesses and develop themselves under the guidance of a trained facilitator or mentor. Case studies and hypothetical exercises are useful in making sure that the leadership theories can be translated into good practices.

\section{REFERENCES}

Akunga, E., Midi, L., Mogere, J., Muia, D. M., Mutahi, D., Mwangi, M. W., et al. (2000). The impact of HIV/AIDS on education in Kenya, and the potential for using education in the widest sense for the prevention and control of HIV/AIDS: A Government of Kenya and UNICEF Kenya Country Office study: Final Report November 2000. Kenya: Government of Kenya and UNICEF. The United Nations Children's Fund website: http://www.unicef.org/ evaldatabase/files/KEN_00-800.pdf.

Bass, B. M. (1985). Leadership and performance beyond expectations. New York: The Free Press.

Boyede, G. O., Lesi, F. E. A., Ezeaka, V. C., \& Umeh, C. S. (2013). Impact of sociodemographic factors on cognitive function in school-aged HIV-infected Nigerian children. HIV/AIDS (Auckland, N.Z.), 5, 145-152. 
Buot, M.-L. G., Docena, J. P., Ratemo, B. K., Bittner, M. J., Burlew, J. T., Nuritdinov, A. R., Robbins, J. R. (2014). Beyond race and place: distal sociological determinants of HIV disparities. PLoS ONE, 9(4), e91711.

Cohen, S., ter Stege, J. A., Geurtsen, G. J, Scherpbier, H. J., Kuijpers, T. W., Reiss, P., ... Pajkrt, D. (2015). Poorer cognitive performance in perinatally HIV-infected children versus healthy socioeconomically matched controls. Clinical Infectious Diseases, 60(7), 1111-1119.

Conway, M. (2005). HIV in schools: Good practice guide to supporting children infected or affected by HIV. London, UK: National Children's Bureau. Retrieved from http://www.ncb.org.uk/media/904943/hiv_in_schools__good_practice_guide.pdf.

Creswell, J. W. (2014). Research design: Qualitative, quantitative, and mixed methods approaches (4th ed.). Thousand Oaks, CA: SAGE Publications.

Elm, D. R. (2003). Honesty, spirituality, and performance at work. In R. A. Giacolone \& C. L. Jurkiewicz (Eds.), Handbook of workplace spirituality and organizational performance (pp. 277-288). New York: M.E. Sharpe.

Hatch, J. A. (2002). Doing qualitative research in education settings. Albany, NY: State University of New York Press.

Kelly, M. J. (2000). What HIV/AIDS can do to education, and what education can do to HIV/AIDS. UNAIDS. Retrieved from http://sedosmission.org/old/eng/kelly_1.htm.

Marshall, C., \& Rossman, G. B. (2010). Designing qualitative research (5th ed.). Thousand Oaks, CA: SAGE Publications.

Ministry of Education Malaysia. (2012). Malaysia Education Blueprint 2013-2025: National Education Policy. Putrajaya: Ministry of Education Malaysia. Retrieved from http://www.moe.gov.my/userfiles/file/PPP/PreliminaryBlueprint-Eng.pdf.

Ministry of Education Malaysia. (n.d.). Special education. Retrieved from https://www.moe.gov.my/index.php/en/pendidikan-khas.

Ministry of Health Malaysia. (2015). National Strategic Plan: Ending AIDS 2016-2030. Putrajaya: Ministry of Health Malaysia. Retrieved from http://www.moh.gov.my/images/gallery/Report/MalaysiaNSPEA201620302.3(Final_27Nov)_printed\%20version.pdf.

Ministry of Health Malaysia. (2016). The Global AIDS Response Progress Report 2016. Putrajaya: Ministry of Health Malaysia. Retrieved from http://www.moh.gov.my/images/gallery/Report/Malaysia\%20GARPR\%2020 16_Final.pdf.

Raihani. (2008). An Indonesian model of successful school leadership. Journal of Educational Administration, 46(4), 481-496.

Richter, L. (2004). The impact of HIV/AIDS on the development of children. In R. Pharaoh (Ed.), A Generation at Risk: HIV/AIDS, Vulnerable Children and Security in Southern Africa (pp. 9-32). Pretoria: Institute for Security Studies. Retrieved from https://www.issafrica.org/uploads/Mono109.pdf.

Sahenk, S. S. (2010). Characteristics of the headmasters, teachers and students in an effective school. Procedia-Social and Behavioral Sciences, 2(2), 4298-4304.

Soulis, S.-G. (2009). Effective special teacher characteristics: perceptions of preschool special educators in Greece. European Journal of Special Needs Education, 24(1), 91-101. 
Tameside Metropolitan Borough Council. (n.d.). HIV and AIDS-Guidance for schools. Retrieved from https://www.tameside.gov.uk/AdultServices/HIV-and-AIDSGuidance-for-Schools\#6.

Tham, J. S., \& Zanuddin, H. (2015). Religion and media: A case study of Utusan Malaysia's response to HIV/AIDS. Continuum: Journal of Media \& Cultural Studies, 29(1), 121-133.

United Nations Educational, Scientific and Cultural Organization (UNESCO). (1990). World Declaration on Education for All and the Framework for Action to Meet Basic Learning Needs. Paris: UNESCO. Retrieved from http://unesdoc.unesco.org/images/0012/001275/127583e.pdf.

United Nations General Assembly. (2001). Declaration of Commitment on HIV/AIDS "Global Crisis - Global Action". United Nations. Retrieved from http://www.un.org/ga/aids/docs/aress262.pdf.

Velarde, J. (2017) Instructional leadership practices in international schools in Malaysia: A case study. International Online Journal of Educational Leadership, 1(1), 90-117. Doi:10.22452//iojel.vol1no1.5

Veeriah, J., Chua, Y. P., Siaw, Y. L. (2017). Principal's transformational leadership and teachers' affective commitment in primary cluster schools in Selangor. International Online Journal of Educational Leadership, 1(1), 60-89. Doi:10.22452//iojel.vol1no1.4

Warren, S. R. \& Kelsen, V. E. (2013). Leadership coaching: Building the capacity of urban principals in underperforming schools. Journal of Urban Learning, Teaching, and Research, 9, 18-31.

Wong, L.-P., Chin, C.-K. L., Low, W.-Y., \& Jaafar, N. (2008). HIV/AIDS-related knowledge among Malaysian young adults: Findings from a nationwide survey. Journal of the International AIDS Society, 10, 148.

Woods, E. H. J., \& Martin, B. N. (2016). What leadership behaviors were demonstrated by the principal in a high poverty, high achieving elementary school? Cogent Education, 3(1), 1172935. 